\title{
The Evaluation of the Fatigue and Thermocycling Effects on the Maximum Loading and Unloading Force of the CuNiTi Wire
}

\author{
Reza Jelodar, ${ }^{1, *}$ Farhad Shafiei, ${ }^{2}$ and Angela Yalda Rezaei ${ }^{3}$ \\ ${ }^{1}$ Department of Orthodontics, Zanjan University of Medical Sciences, Zanjan, IR Iran \\ ${ }^{2}$ Department of Biomaterials Science, Tehran University of Medical Sciences, Tehran, IR Iran \\ ${ }^{3}$ Deptist, Tehran, IR Iran \\ *Corresponding author: Reza Jelodar, Department of Orthodontics, Zanjan University of Medical Sciences, Zanjan, IR Iran. E-mail: reza_jsn@yahoo.com
}

Received 2015 November 14; Accepted 2015 December 12.

\begin{abstract}
Background: In the oral environment orthodontic wires will be subjected to thermal fluctuations and repeated loading (fatigue). Objectives: The aim of this study is to evaluate the thermocycling and fatigue effect on the CuNiti wires.

Materials and Methods: Samples of CuNiti wires, 0.014 round, were divided into four groups: 1, Fatigue loading; 2, Fatigue and thermocycling; 3, thermocycling; 4, control. The groups involved in fatigue loading by determined protocol $(0.5 \mathrm{~mm}$ deflection, $1 \mathrm{~Hz}$ frequency) also thermocycling performed by this method: bath time (90 seconds), transfer time (15 seconds) and temperature range: 5 55C.after these procedure, fatigue and thermocycling effects on the maximum loading force(MLF)and maximum unloading force (MULF) assessed with a 3-point bending test.

Results: In this study, the amounts of MLF in group 1 and 2 were significantly different with themselves and control group, but in the control group, the results were not significantly different with thermocycling group. Also the amounts of MLF in the group 3 were not different by the group 1 and 2 . For the MULF, the results of group 1 and 2 were significantly different with the control and thermocycling group. Difference between fatigue and control groups for hysteresis loading (difference between MLF and MULF) variable was not significant while other two by two comparisons were significant.

Conclusions: The fatigue loading increased MLF and MULF, but the effect of thermocycling was complicated on the MLF. Thermocycling also did not affect the MULF, but decreased hysteresis loading.
\end{abstract}

Keywords: CuNiTi Alloy, CuNiTi Wires, Orthodontic Wires, Hysteresis Loading, Load Deflection Rate(LDR)

\section{Background}

Ideal arch wires for aligning and leveling of dental arch should have the ability to move teeth with light forces and long periods without tissue damage. NiTi arch wires due to the low load deflection rate (LDR), generate continuous light forces and greater control on forces. One of the interesting arch wires which have been presented in three models by Ormco Corporation is CuNiTi wire, which have important applications in Damon self-ligating system (1).

During orthodontic treatment, occlusal contact between the dental arches, while swallowing and chewing makes forces, which are applied to arch wires. Frequent occlusal contacts and tooth mobility that occurs during the initial alignment can cause fatigue effect on the arch wires (2). Therefore, it is important to evaluate the fatigue effect of occlusal contacts on the arch wires in the aligning stage.

Although several studies (2-4) have examined the mechanical properties and phase transformation changes on NiTi wires but a few information about the effect of fatigue (repeated loading) have been presented specially on the CuNiti wires (2-4).

Van Aken et al. (2) studied the effect of fatigue in different wires such as classic Nitinol, A- NiTi, Nitinol super elastic and stainless steel.

Based on their results, the fatigue on wires has no effect on the unloading force of the arch wires. Iijima et al. (5) investigated the mechanical behavior of NiTiCr, NiTi and NiTiCuCr wires, at different temperatures and stress and showed that the temperature elevation above austenite finish temperature (AF) of NiTi wires due to the austenite phase formation increases maximum loading force (MLF) and maximum unloading force levels (MULF).In another study, Gil and Planell (6) showed that adding small amounts of cupper decreases loading hysteresis (subtracted level of ascending and descending parts of the LDR curve) which indicate the presence of austenite and martensite phase in lower temperature, This study also reviewed the influence of 200 Cyclic loading on NiTi wires and CuNiTi wires, and showed that cycling loading

Copyright (C) 2015, Iranian Journal of Orthodontics. This is an open-access article distributed under the terms of the Creative Commons Attribution-NonCommercial 4.0 International License (http://creativecommons.org/licenses/by-nc/4.0/) which permits copy and redistribute the material just in noncommercial usages, provided the original work is properly cited. 
on NiTi wires increases the Martensite start temperature (Ms), Austenite finished temperature (Af) and reduces the Hysteresis loading rate ,While cyclic loading will not cause a significant change in transitional temperature rate (TTR), Berzins and Roberts (7) concluded that thermal cycles induce the qualitative and quantitative changes in phase transformation rate, particularly on CuNiTi wires. These changes increase the temperature of austenite formation and reduce the formation temperature of martensite which is caused by dislocation and the interaction between the deposits. These are in agreement with Stroz et al. (8) and Tadaki et al. (9).

In order to the heat activation characteristics in the $\mathrm{Cu}$ NiTi wires, variable temperatures in oral cavity (due to the consumptions of various food) (10) and the effects of fatigue of wires in different solutions under $37^{\circ} \mathrm{C}(11-17)$, this study tried to evaluate the effect of thermal cycles and fatigue simultaneously on the CuNiTi wires.

\section{Objectives}

The aim of this study is to evaluate the thermocycling and fatigue effect on the CuNiti wires.

\section{Materials and Methods}

Eighty pieces of (Ormco, Glendora, CA91740) CuNiTi 35 $C$ wire were used with round cross section and the diameter of 0.014 Inch and with the length of $20 \mathrm{~mm}$ which was prepared (cut) from the straight part of the posterior segment in the arch wire in 4 groups (20 segments per group).

One group involved fatigue process (100.000 Fatigue cycles, and $0.5 \mathrm{~mm}$ amount of bending with frequency of $1 \mathrm{~Hz}$ ) (2), (Figure 1).

Another group was for the thermocycling process with bath time: 90 seconds and transfer time 15 seconds in the temperature range of $5-55^{\circ} \mathrm{C}(16)$.

In the third group, thermocycling and fatigue process was applied simultaneously, based on the quoted protocol (Figure 2).

The fourth group was considered as control. To unify the ligation technique and the friction, premolar self-ligating brackets of Damon system was used for performing fatigue tests. A template was designed in various studies the bracket width is considered to be $6.5 \mathrm{~mm}$, to simulate the dental arch, in this template the space between brackets was13 mm plus the width of a bracket (2), (Figure 3).

After samples preparation, they were placed in the template and put them in the fatigue machine (Instron, 8500 , England). For the bending of $0.5 \mathrm{~mm}$, a beam with the width of a bracket is made to exert bending in the middle of wires (Figure 4).

In the current study, required thermocycles was 513 based upon the total fatigue test time.

In the end of stages, 3-Point bending test was conducted in the laboratory under specific temperature $\left(37^{\circ} \mathrm{C}\right)$ by SANTAM (STM 20-Iran).

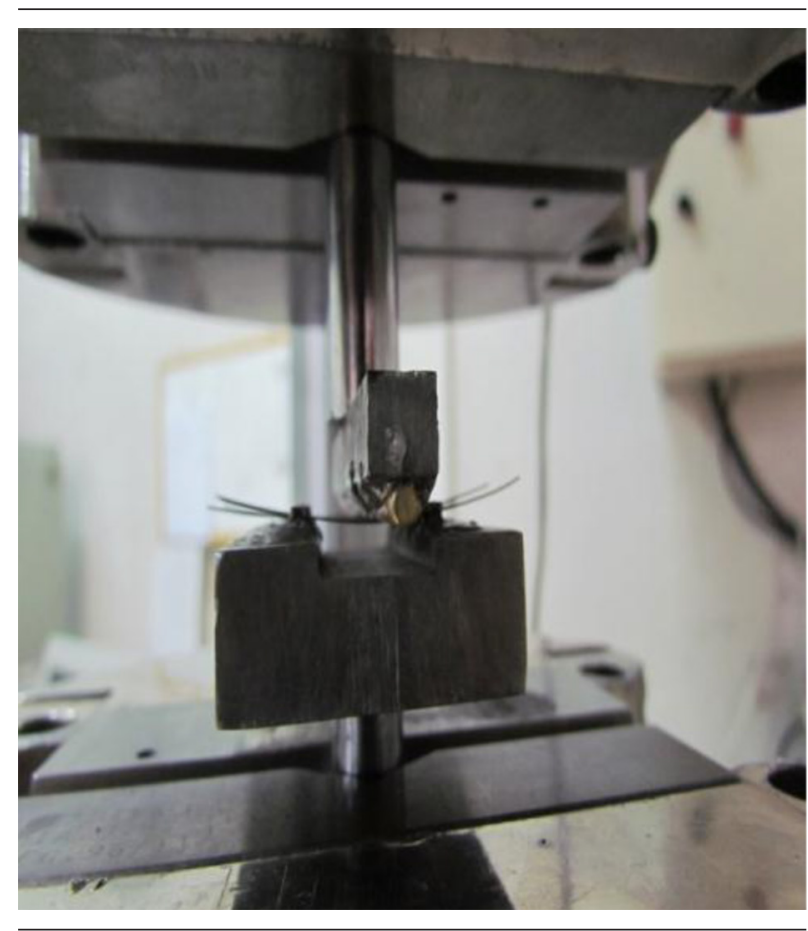

Figure 1. Fatigue Process

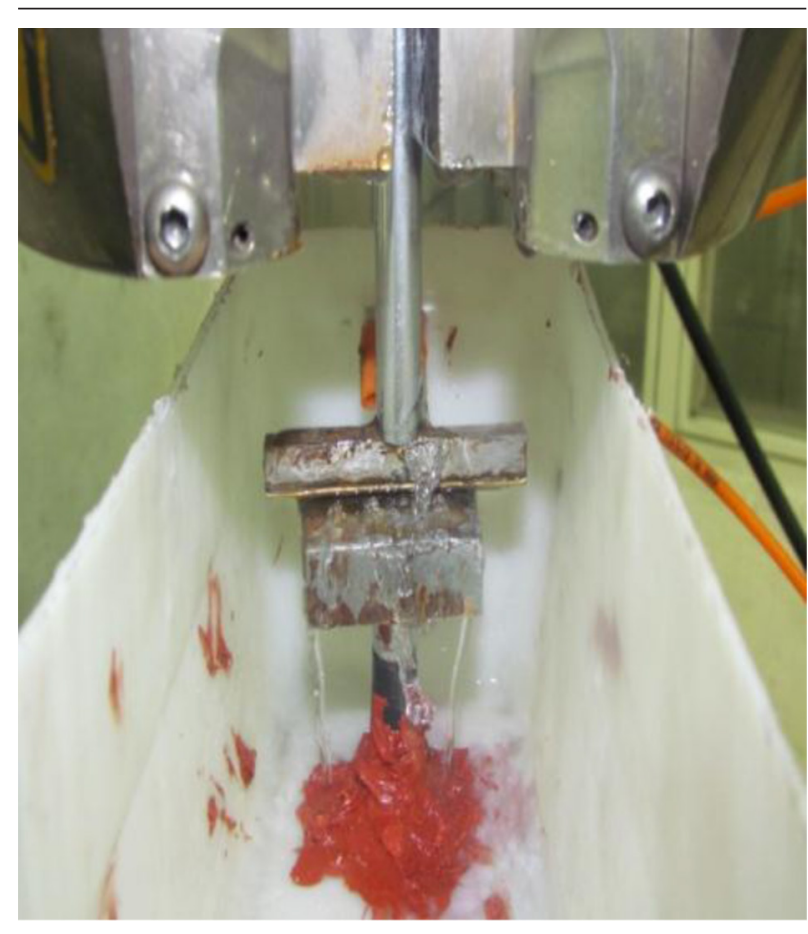

Figure 2. Thermocycling and Fatigue Process

During the 3-point bending test, the previous template was used and it was done with $2 \mathrm{~mm} /$ minute speed and 3 $\mathrm{mm}$ maximum bending in $37^{\circ} \mathrm{C}$. To control the temperature, the template was placed in a container with $37^{\circ} \mathrm{C}$ water where the temperature was checked by a thermometer (Figure 5). 


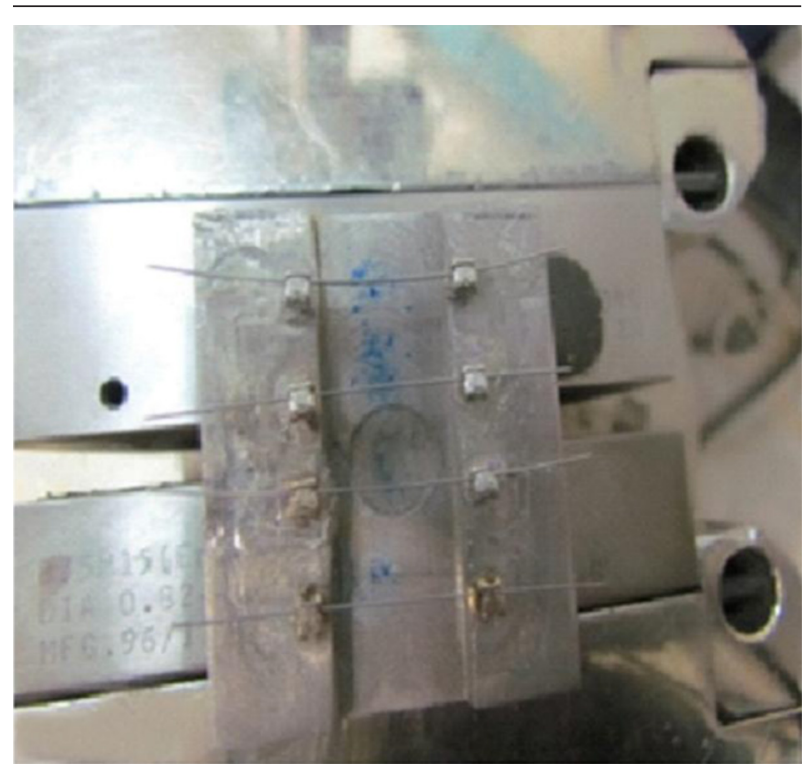

Figure 3. Dental Arch

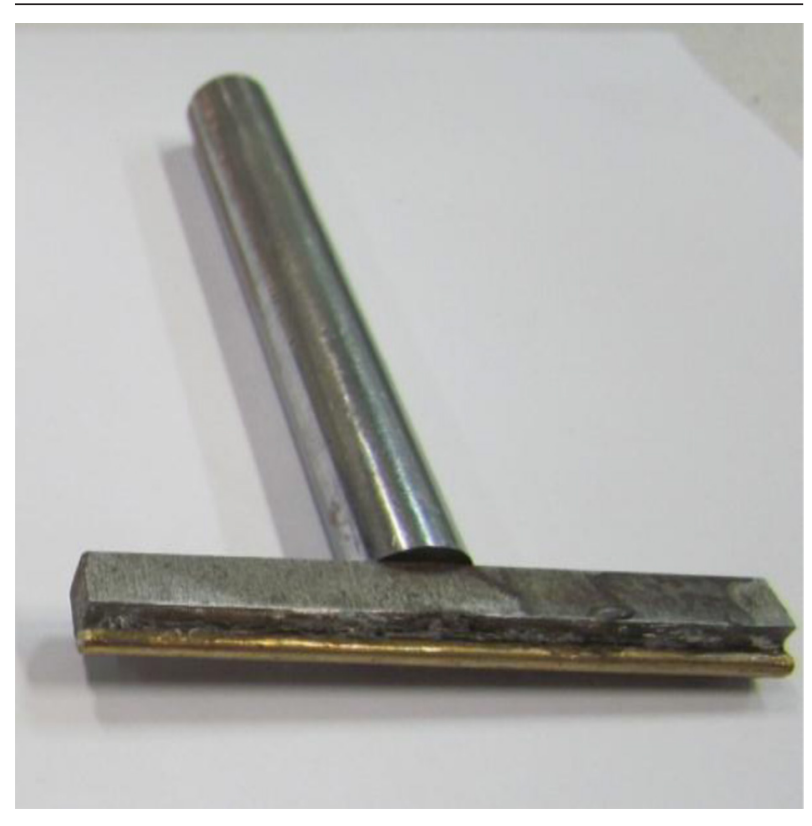

Figure 4. Template

After this stage, the values of MLF (MAXIMUM loading force) and MULF (maximum unloading force) were calculated based on the graphs plotted by SANTAM software.

Afterwards, the MLF and MULF rates were reported as mean and standard deviation.

In the evaluation of the effect of two variables thermocycling and fatigue on hysteresis loading, Maximum loading force, and maximum unloading force, Two-way ANOVA test method was used. In hysteresis loading and MLF, concerning the significance of their interaction, one way ANOVA test was used (Statistically significance was considered to be at $\mathrm{P}=0.05$ ).

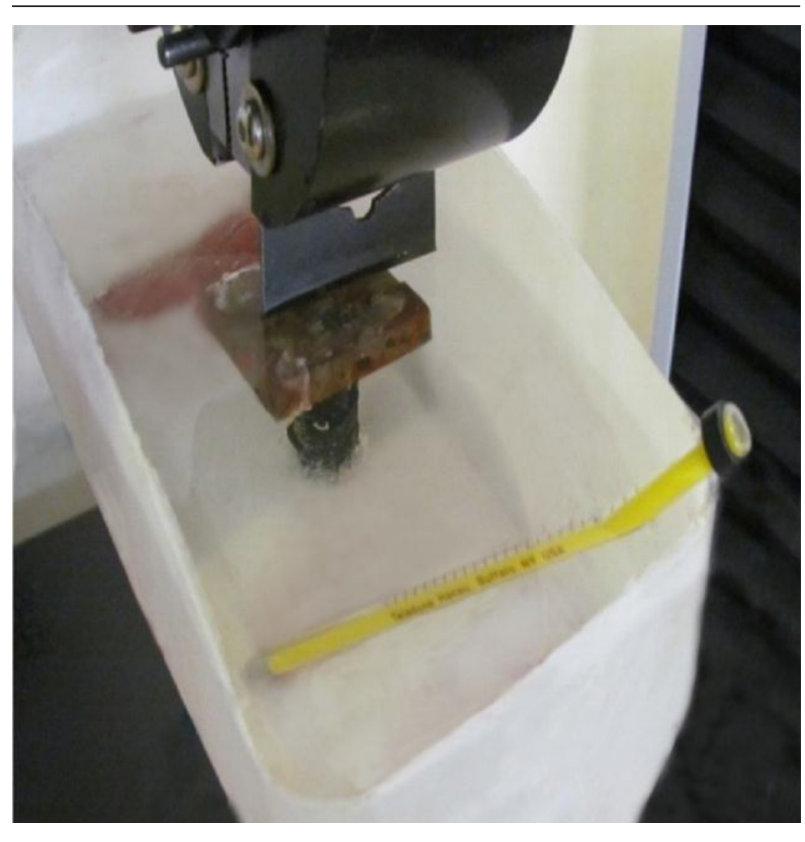

Figure 5.3-Point Bending Test

\begin{tabular}{lccc}
\hline \multicolumn{3}{l}{ Table 1. The Mean Values of MLF in Different Groups } \\
\hline Fatigue & Termocyc & Mean \pm SD & N \\
\hline No & No & $2.6294 \pm 0.15961$ & 20 \\
& Yes & $2.4565 \pm 0.31522$ & 20 \\
\hline Yes & Total & $2.5384 \pm 0.26530$ & 40 \\
\hline & No & $2.8316 \pm 0.22307$ & 20 \\
\hline & Yes & $2.3556 \pm 0.14452$ & 20 \\
\hline & Total & $2.6000 \pm 0.30483$ & 40 \\
\hline & No & $2.7332 \pm(0.021772$ & 40 \\
\hline & Yes & $2.4087 \pm 0.25145$ & 40 \\
\hline
\end{tabular}

\section{Results}

Results of the MLF have been shown in Table 1.

MLF in four groups was not identical, the observed differences between the groups of fatigue and thermocycling and fatigue together $(\mathrm{P}<0.001)$ and with the control group was significant $(\mathrm{P}=0.003, \mathrm{P}=0.04)$.

Difference between thermocycling group and three other groups were not significant $(\mathrm{P}=0.09, \mathrm{P}=0.51$ ).

The amount of MULF in four groups were calculated and presented in Table 2.

Based on our results, repeated loading affects the MULF $(\mathrm{P}<0.001)$, while thermocycling had no tangible impact on MULF values $(\mathrm{P}=0.09)$. 
Jelodar R et al.

\begin{tabular}{lccc}
\hline \multicolumn{4}{l}{ Table 2. The Mean Values of MULF in Different Groups } \\
\hline Fatigue & Termocyc & Mean \pm SD & N \\
\hline No & No & $1.0912 \pm 0.13014$ & 20 \\
& Yes & $1.1595 \pm 0.23815$ & 20 \\
\hline \multirow{4}{*}{ Yes } & Total & $1.1272 \pm 0.19521$ & 40 \\
& No & $1.3233 \pm(0.19983$ & 20 \\
\hline \multirow{2}{*}{ Total } & Yes & $1.4072 \pm 0.15056$ & 20 \\
& Total & $1.3641 \pm 0.18023$ & 40 \\
& No & $1.2137 \pm 0.20515$ & 40 \\
\hline & Yes & $1.2800 \pm 0.23414)$ & 40 \\
\hline
\end{tabular}

Table 3. The Mean Values of Hystresis Loading in Various Groups

\begin{tabular}{lccc}
\hline Term & Fatigue & Mean \pm SD & N \\
\hline No & No & $1.5429 \pm 0.12071$ & 20 \\
& Yes & $1.5083 \pm 0.14384$ & 20 \\
& Total & $1.5247 \pm 0.13270$ & 40 \\
Yes & No & $1.3026 \pm 0.13625$ & 20 \\
& Yes & $0.9483 \pm 0.09697$ & 20 \\
\hline \multirow{2}{*}{ Total } & Total & $1.1303 \pm 0.21437$ & 40 \\
& No & $1.4161 \pm 0.17611$ & 40 \\
& Yes & $1.2359 \pm 0.30871$ & 40 \\
\hline & Total & $1.3248 \pm 0.26638$ & 80 \\
\hline
\end{tabular}

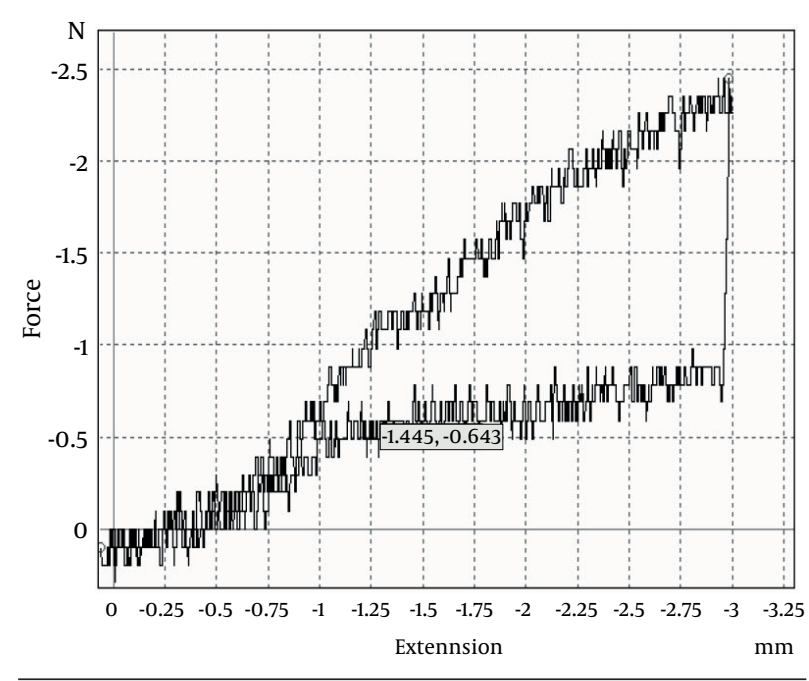

Figure 6. LDR Curve in Control Group

Numeric findings based on hysteresis loading (HL) for the groups are presented in Table 3.

Difference between fatigue and control groups for hysteresis loading (difference between MLF and MULF) variable was not significant $(\mathrm{P}=0.84)$ while other two by two comparisons were significant $(\mathrm{P}<0.001)$ (Table 3$)$.
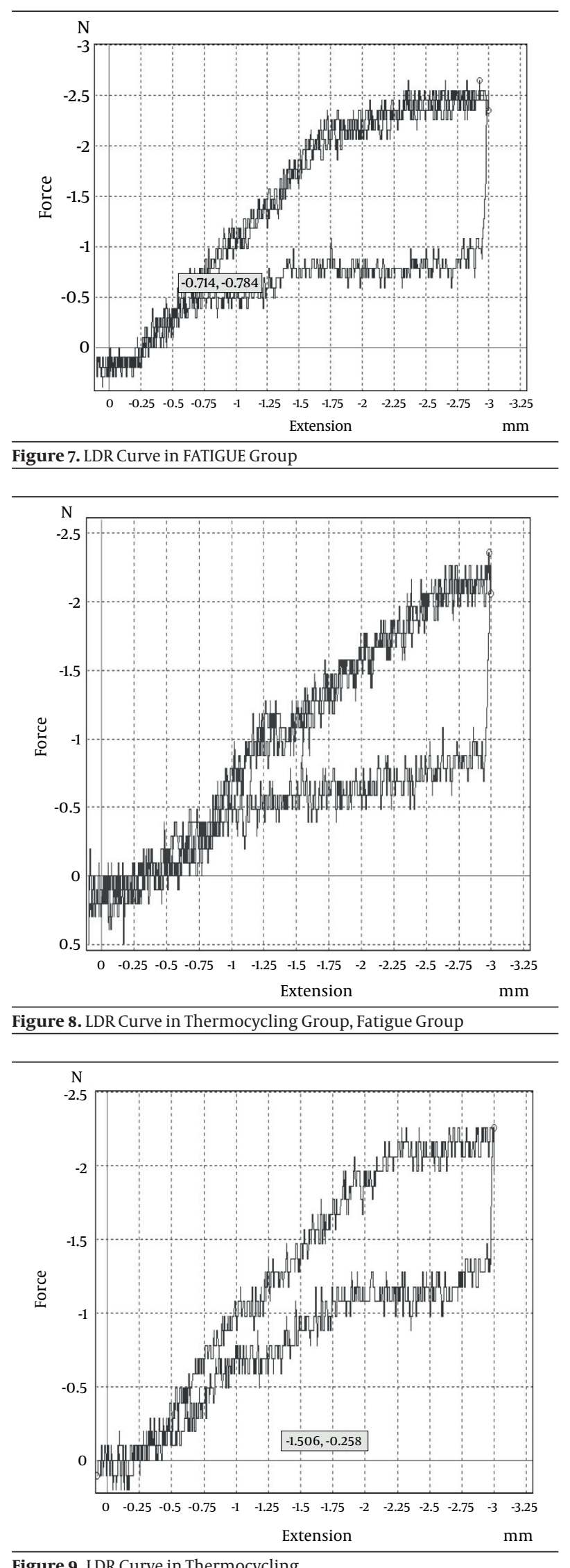

Figure 9. LDR Curve in Thermocycling 


\section{Discussion}

In this study, the effects of fatigue (repeated loading) and thermocycling on the amount of (maximum loading force) MLF and (maximum unloading force) MULF of the $\mathrm{CuNiTi}$ wires were examined $\left(\mathrm{AF}=35^{\circ} \mathrm{C}\right)$.

Loading force is the amount of force that engages the wire in the bracket while unloading force is the force that can be imported by wire to the teeth, conditional that the wire is not bent beyond the elastic limit (2).

Exertion of repeated loading equal to $0.5 \mathrm{~mm}$ on the wires in this study was to simulate the condition of teeth in the dental arch while the arch wire are bent under occlusal periodic contacts and tooth displacement in the PDL (2).

In oral environment, the average rate of occlusal contacts is 2,000 times per day $(18,19)$.

Considering the duration of wire stay (2 months) in Damon system, the number of fatigue cycles was considered 100000 (1).

The provided thermocycling protocol was transfer time of 15 seconds, bath time of 90 seconds in the temperature range of $5-55^{\circ} \mathrm{C}$ for 513 cycles. Tonner and Waters (20) have emphasized that Super elastic alloys need to be bent $2 \mathrm{~mm}$ minimally for length of $13 \mathrm{~mm}$ wires to show their superelastic behaviour, Therefore; in the present study 3-Point bending test was performed with $3 \mathrm{~mm}$ bending. Based on current study, MLF was not identical in all four groups, but the difference observed was in the groups of Fatigue, thermocycling and fatigue together and with the control group was significant, while thermocycling group had no significant differences with three other groups. MULF showed that fatigue has impacts on the MULF but no effect on thermocycling.

Given the above values, we can conclude that the repeated loading (Fatigue) increases MLF and MULF while thermocycling had no uniform impact on MLF and MULF which can be due to low cycles of thermocycling in this study.

Van Aken (2) concluded that repeated loading has no effect on unloading force, which is against our findings, we have to mention that his study was not on CuNiTi wires. According to Berzins, thermocycling through increased dislocations and its interactions between the deposits in the microscopic structure of CuNiTi wires reduced Ms (martensite started) and increases AF (austenite finish) (7). The existence of these deposits in the CuNiTi wires structure has been documented in various studies $(7,21$, 22). A reason to formation of these deposits is the reaction of NiTi alloy with oxygen in the surrounding environment (20).

Moreover, several studies have reported that these deposits affect the formation of martensite phase in the $\mathrm{Cu}$ NiTi alloys (21).

Gil and Planell (6) concluded that cyclic loading on NiTi wires reduces the stress for transformation of the austenite phase into martensite, While it has no effect on $\mathrm{Cu} \mathrm{NiTi}$ wires, as well cyclic loading increases the Ms (martensite started) and As (austenite started) in the NiTi wires, while the As and Ms in Cu NiTi wire does not change.

Results of this study does not confirm Gil and Planell (6), perhaps due to fewer cyclic loading in Gil and Planell study.

As noted in this study, it appears that increase in MULF and MLF is due to the decrease of Af, after Fatigue procedure. AF reduction causes increasing and stabilizing of austenite phase and this events mean an increased energy requirment for the formation of SIM (stress induced martensite) phase.

According to Ijima et al. (5) $\mathrm{Cu}$ NiTi wire with $\mathrm{Af}=37^{\circ} \mathrm{C}$ the amount of MLF and MULF increases with increasing temperature of environment (relative reduction of Af).

Also loading hysteresis rate will increase (difference between MLF and MULF) with increasing temperature of environment (the temperature difference and Af) and stabilizing the austenite phase. According to Burstone and Goldberg (3), the more amount of Af in the environment temperature the less energy is required for making the SIM (stress induced martensite) and vice versa.

The evaluation of the LDR curves in current study showed that the amount of Loading hysteresis in the fatigue and control group are similar and significantly greater than the group that were thermocycled, which seems to be consistent with the results of Burstone and Iijima $(3,5)$.

Reduce hysteresis loading in thermocycled groups can be due to an increase in Af and thus reduction in austenite phase rate to martensite phase. Af increases based on different studies $(7,9)$ arising from making new dislocations and deposits interaction in the $\mathrm{Cu}$ NiTi structure. The Intermediate R phase which is at the lower Af temperature of alloy appears to be involved in the induction of dislocations and deposits and causes improvement fatigue resistance (5).

\subsection{Conclusions}

Fatigue increases MLF and MULF. Thermocycling does not have significant impact on MLF and MULF.MLF rate in fatigue and thermocycling groups were reduced significantly. Fatigue impact on hysteresis loading is not significant while thermocycling cause reduction in hysteresis loading.

\section{References}

1. Graber LW, Vanarsdall RL, Vig KWL. Orthodontics: current principles and techniques. Elsevier Health Sciences; 2011.

2. Van Aken CA, Pallav P, Kleverlaan CJ, Kuitert RB, Prahl-Andersen B, Feilzer AJ. Effect of long-term repeated deflections on fatigue of preloaded superelastic nickel-titanium archwires. Am J Orthod Dentofacial Orthop. 2008;133(2):269-76. doi: 10.1016/j.ajodo.2005.10.030. [PubMed: 18249294]

3. Burstone C, Goldberg AJ. Maximum forces and deflections from orthodontic appliances. Am J Orthod. 1983;84(2):95-103. doi: 10.1016/0002-9416(83)90173-2. [PubMed: 6576645]

4. Craig RG, Powers J. Restorative dental materials. 11th ed. Mosby ; 2002.

5. Iijima M, Ohno H, Kawashima I, Endo K, Mizoguchi I. Mechanical 
behavior at different temperatures and stresses for superelastic nickel-titanium orthodontic wires having different transformation temperatures. Dental Materials. 2002;18(1):88-93. [PubMed: 11740969]

6. Gil FJ, Planell JA. Effect of copper addition on the superelastic behavior of $\mathrm{Ni}$ - Ti shape memory alloys for orthodontic applications. Dent Mater.1999;48(5):682-8.

7. Berzins DW, Roberts HW. Phase transformation changes in thermocycled nickel-titanium orthodontic wires. Dent Mater. 2010;26(7):666-74. doi: 10.1016/j.dental.2010.03.010. [PubMed: 20371115]

8. Stroz D, Bojarski Z, Ilczuk J, Lekston Z, Morawiec H. Effect of thermal cycling on as-quenched and aged nickel-rich Ni-Ti alloy.Journal of Materials Science.1991;26(7):1741-8. doi:10.1007/bfo0543596.

9. Tadaki T, Nakata Y, Shimizu K, rsquo. ichi Thermal Cycling Effects in an Aged Ni-rich $\mathrm{Ti}^{\wedge} \mid \wedge$ ndash;Ni Shape Memory Alloy. Trans Jpn Inst Met. 1987;28(11):883-90. doi:10.2320/matertrans1960.28.883.

10. Longman CM, Pearson GJ. Variations in tooth, surface temperature in the oral cavity during fluid intake. Biomaterials. 1987;8(5):411-4. doi: 10.1016/0142-9612(87)90016-0. [PubMed: 3676430]

11. Santoro M, Nicolay OF, Cangialosi TJ. Pseudoelasticity and thermoelasticity of nickel-titanium alloys: a clinically oriented review. Part I: Temperature transitional ranges. Am J Orthod Dentofacial Orthop. 2001;119(6):587-93. doi: 10.1067/mod.2001.112446. [PubMed: 11395701]

12. Bourauel C, Scharold W, Jager A, Eliades T. Fatigue failure of as received and retrieved NiTi orthodontic archwires. Dent Mater 2008;24(8):1095-101. doi: 10.1016/j.dental.2007.12.007. [PubMed: 18289660]

13. Harris EF, Newman S, Nicholson JA. Nitinol arch wire in a simulated oral environment. Changes in mechanical properties. Am. J Orthod.1988;93(6):508-13. doi:10.1016/0889-5406(88)90080-7.

14. HudginsJJ,BagbyMD,Erickson LC.The effect of long-term deflection on permanent deformation of nickel-titanium archwires. Angle Orthod.1990;60(4):283-8. doi:10.1043/0003-3219(1990)060<0283:TEO LDO>2.0.CO;2. [PubMed:2256566]

15. Lee $\mathrm{SH}, \mathrm{Chang} \mathrm{YI}$. Effects of recycling on the mechanical properties and the surface topography of nickel-titanium alloy wires. Am J Orthod Dentofacial Orthop. 2001;120(6):654-63. doi: 10.1067| mod.2001.118997. [PubMed: 11742311]

16. Prymak O, Klocke A, Kahl-Nieke B, Epple M. Fatigue of orthodontic nickel-titanium (NiTi) wires in different fluids under constant mechanical stress. Mater Sci Eng Proc Conf. 2004;378(12):110-4. doi:10.1016/j.msea.2003.10.332.

17. Drescher D, Bourauel C, Sonneborn W, Schmuth GP. [The longterm fracture resistance of orthodontic nickel-titanium wires]. Schweiz Monatsschr Zahnmed. 1994;104(5):578-84. [PubMed: 8023109]

18. Kincaid RM. The frequency of deglutition in man: its relationship to overbite. Angle Orthod. 1951;21(1):34-43. doi: 10.1043/0003-3219(1951)021<0034:TFODIM>2.0.CO;2. [PubMed: 14838361]

19. Straub WJ. Malfunction of the tongue: Part II. The abnormal swallowing habit: Its causes, effects, and results in relation to orthodontic treatment and speech therapy. Am J.Orthod. 1961;47(8):596-617.

20. Tonner RI, Waters NE. The characteristics of super-elastic Ni-Ti wires in three-point bending. Part I: The effect of temperature. EurJ Orthod.1994;16(5):409-19. [PubMed: 7805815]

21. Brantley WA, Guo W, Clark WA, Iijima M. Microstructural studies of 35 degrees $\mathrm{C}$ copper $\mathrm{Ni}$-Ti orthodontic wire and TEM confirmation of low-temperature martensite transformation. Dent Mater. 2008;24(2):204-10. doi: 10.1016/j.dental.2007.04.004. [PubMed: 17561249]

22. Fukuda T, Kakeshita T, Saburi T. Copper Content Dependence of the Lattice Parameters of Ti(NiCu)2. Materials Transactions, JIM. 2000;41(7):837-40. doi: 10.2320/matertrans1989.41.837. 